\title{
A generic problem
}

\author{
Stephen B Hanauer
}

I should say upfront that I have potential conflicts of interest. I continue to consult with numerous pharmaceutical companies in relation to drug development, clinical trials, patent infringements and even marketing. In addition, my salary from the University of Chicago is linked to clinical service and, hence, reimbursement from thirdparty payers, including Medicare. I make this declaration since (unless subsequent legislation reverses the plan) a $5.1 \%$ cut in the physicianreimbursement rate will take effect on 1 January 2007 despite the increased administrative burdens that are continually being implemented, which affect our ability to care for patients. I am also a believer in competition.

Despite these-pro and con-conflicts and my naiveté with respect to current practices for patent protection and payoffs to the manufacturers of generic drugs from the manufacturers of the branded version of the same drug, I was distressed to read Miriam Shuchman's perspective on "Delaying generic competition-corporate payoffs and the future of Plavix" (N Engl J Med (2006) 355: 1297-1300). Dr Shuchman highlights how the producers of the world's second-best-selling branded drug (sales of more than US $\$ 6$ billion in 2005, and taken by 48 million Americans) paid $\$ 40-60$ million to a company not to market their generic clopidogrel, which was priced $20 \%$ lower than the brand-named product. Shuchman's article also mentions how the producers of branded formulations of diltiazem and terazosin paid $\$ 100$ million and $\$ 54$ million, respectively, to keep generic versions off the US market.

As stated, I am in favor of competition, and of the enforcement of appropriate legislation to support patent protection for branded products. I understand the drug development process and am aware of the $R \& D$ costs of
Drug

companies

need to be

prevented from

paying off their

competitors

to stop the

marketing

of...generic

versions

of branded

drugs, once

the patents

that protect

the developers

have expired

SB Hanauer is Editorin-Chief of Nature Clinical Practice Gastroenterology \& Hepatology.

\section{Competing interests}

The author has declared associations with the following companies: Abbott Laboratories, Centocor, Prometheus Labs and UCB. See the article online for full details of the relationship.

www.nature.com/clinicalpractice doi:10.1038/ncpgasthep0659 bringing novel compounds to the market. However, in an era where overall health-care costs are rising and comprise an increasing proportion of domestic spending, the concept of paying off companies that manufacture generic versions of brand-named drugs not to market equally safe and effective therapeutic compounds after the patent of the branded compound has expired (or has been found invalid) is outrageous! Obviously, as it is whenever attorneys become involved, the case is more complex than I have stated because of loopholes in the current Hatch-Waxman legislation (The Drug Price Competition and Patent Term Restoration Act of 1984, which was designed to promote the development of generic drugs while retaining financial incentives for research and development of new drugs). Yet, these corporate agreements do not pass the 'red face' test and reflects corporate greed by both parties: those protecting the brand and those who will earn more money by not marketing a generic drug than by competing in the marketplace. The practice is clearly anticompetitive and as the Federal Trade Commissioner Jon Leibowitz is quoted as saying in Schuman's article "...For the most part, consumers are going to be left ... footing the bill, while pharmaceutical companies make these anticompetitive agreements that keep drugs out of the market." Of course, since such a large proportion of drug costs are born by Federal and state governments, we are all (individual) consumers in this marketplace.

Clearly, further legislation is needed. Drug companies need to be prevented from paying off their competitors to stop the marketing of less costly, yet equally safe and efficacious, generic versions of branded drugs, once the patents that protect the developers have expired. 